\title{
THE CIRCULAR ECONOMY IMPACT ON SMALL TO MEDIUM ENTERPRISES
}

\author{
JOHN THORLEY ${ }^{1}$, JOSE A. GARZA-REYES ${ }^{2} \&$ ANTHONY ANOSIKE $^{2}$ \\ ${ }^{1}$ Department of Engineering, University of Derby, UK \\ ${ }^{2}$ Centre for Supply Chain Improvement, University of Derby, UK
}

\begin{abstract}
In recent years, the literature surrounding the circular economy has grown. While the notion of reducing, recycling and reusing have become adopted practices in many organisations under the umbrella of sustainability, having a circular economy is arguably the next generation step, in terms of sustainability. A systematic literature review on the circular economy identified a gap in the research, regarding the impact at the micro level to be placed on small to medium enterprises. The research concludes that a paradigm shift in circular thinking at the micro level is required, and that further research is needed to identify new skills, resources, approaches, and business models to enable subject matter experts (SMEs) to adopt a circular practice.

Keywords: circular economy, literature review, impact and challenges, medium business, small business, subject matter expert, sustainability, systematic review.
\end{abstract}

\section{INTRODUCTION}

A circular economy is a model for economic growth that aims at environmental protection, pollution prevention and sustainable development. In nature, the concept of waste does not exist; everything is an input to another process in the life cycle. It is on this model that the concept of circular economy was built. Schulte [1] states "Circular economy is not just concerned with the reduction of the use of the environment as a sink for residuals but rather with the creation of self-sustaining production systems in which materials are used over and over again."

The aim of this paper is to explore the impact the circular economy may have on a small to medium enterprise. The "circular economy pushes the frontiers of environmental sustainability by emphasising the idea of transforming products in such a way that there are workable relationships between ecological systems and economic growth" [2].

According to Ayres, "industrial metabolism in industrial ecology refers particularly to the idea of industrial systems working as natural ecosystems" [3]. "This emerging concept of circular economy, is envisioning a future where nothing is wasted; a future where every 'waste' becomes an asset, and no value goes unrecovered; a future where all products at the end of their primary use are recovered and either reused, remanufactured, or recycled for multiple generations, has become more than a reality, but a necessity" [4]. This concept of the $6 \mathrm{R}$ process discusses second, third and fourth generations of recover, redesign and remanufacture of products, likening the process to a helical movement rather than a circular movement [4].

\section{METHODOLOGY}

This literature review is based on a systematic research method that endeavours to capture all material concerned with the research area. We will consider a variety of search strings and combinations to systematically and rigorously investigate the territory. According to Cook et al., "Systematic reviews differ from traditional narrative reviews by adopting a replicable, scientific and transparent process, in other words a detailed technology that aims to minimize bias through exhaustive literature searches of published and unpublished studies and by 
providing an audit trail of the reviewer's decisions, procedures and conclusions." Grant and Booth [6] state that "Gathering research, getting rid of rubbish and summarizing the best of what remains captures the essence of the science of systematic review." This systematic review intends to minimise bias and capture different areas of research associated with the context of the aim of this research. This will enable the author to identify any gap in research knowledge and develop a research strategy to add new knowledge to this area of study.

"A systematic search begins with the identification of keywords and search terms, which are built from the scoping study, the literature and discussions within the review team. The reviewer should then decide on the search strings that are most appropriate for the study. The search strategy should be reported in detail sufficient to ensure that the search could be replicated" [5].

According to Mulrow, "Although sometimes taking considerable time, and almost always requiring perseverance and attention to detail, systematic review has been argued to provide the most efficient and high-quality method for identifying and evaluating extensive literatures." The steps that will be taken are based on a Systematic Literature Review (SLR) technique as follows, as stated by Denyer and Tranfield in 2009, cited by Xavier et al. [7]:

1. Formulation of the research question;

2. Location of studies;

3. Selection and evaluation of studies;

4. Analysis and synthesis and

5. Reporting and use of research results.

\subsection{Formulation of the research question}

Tranfield et al. [5] argue, "The review question is critical to systematic review as other aspects of the process flow from it." They also stress; however, that "It is generally considered unacceptable to plan the literature-review activities closely. A more flexible approach may make explicit what the researcher intends to do as a priority but can be modified through the course of the study."

The research question is: What impact does a circular economy have on a small-tomedium enterprise? It is the intention to use a variety of search strings that best fit the needs of the investigation. A combination of the search criteria below will be used to provide an indepth and rigorous study. It is evident by the research question that there are four key terms that require investigation: framework, circular economy, SMEs and readiness. A SME is a small to medium enterprise, generally consisting of $<250$ employees. Whilst this research may refer to SMEs outside the UK, it is the general intention to be applying any learning and new knowledge dedicated to the research of SMEs within the UK.

For the sake of this research, the terms sustain ${ }^{+}$will not become part of the string search terms. Although there is much overlap with these terms, there is also a fundamental difference. Sauvé et al. [8] argue that the term "sustainable development" is fundamentally grounded in the three R's that are reduce, reuse, recycle; and it is firmly embedded in a linear economy. As the circular economy suggests, its ideology is based on the maximisation of materials and not the linear practice of using virgin raw materials. Sustainable development is indeed a practice that has started to take hold in the manufacturing industry. For the purpose of this research, the following search strings were used (Table 1) and the scope of the review was conducted using electronic databases and search parameters (Table 2). 
Table 1: Keywords and search strings for the Systematic Literature Review.

\begin{tabular}{|l|l|}
\hline Search string themes & Keywords, synonyms and alternatives \\
\hline Circular economy & Framework OR model \\
\hline Frameworks & SME OR manufacturing OR production \\
\hline Small to medium enterprise &
\end{tabular}

Table 2: The scope for the literature review detailing inclusive criteria.

\begin{tabular}{|l|l|}
\hline Criterion & Included \\
\hline Scope for the search & $\begin{array}{l}\text { Elsevier (sciencedirect.com), EBSCO (Business Source } \\
\text { Premier), Emerald (emeraldinsight.com), Taylor \& Francis } \\
\text { online (t\&fonline.com), IEEexplore (ieeexplore.com), Google } \\
\text { Scholar }\end{array}$ \\
\hline Source & Peer reviewed journal articles \\
\hline Search parameters & Keywords appearing in the title \\
\hline Language & English \\
\hline Period & All years to present \\
\hline Relevance & $\begin{array}{l}\text { Literature focusing on frameworks to enable a circular economy } \\
\text { in SMEs }\end{array}$ \\
\hline
\end{tabular}

\subsection{Location of studies}

A decision was taken to use the technique of systematic literature review, to ensure as much data as possible is captured and to ensure that this research is both thorough and replicable. "A systematic search begins with the identification of keywords and search terms, which are built from the scoping study, the literature and discussions within the review team. The reviewer should then decide on the search strings that are most appropriate for the study." [5]. Initially, we looked at similar terms (words) for the same topic. In total, there were 24 different search combinations of three terms per search; however, "systematic simply means that reviewers follow an appropriate (but not standardized or rigid) design and that they communicate what they have done" [9]. As evidenced above, there was a degree of emerging strategy, in terms of the search criteria, based on results and feedback from the original searches. Decisions were taken in order to maintain effectiveness and the efficiency of the research process.

\subsection{Selection and evaluation of studies}

The inclusion and exclusion criteria were applied to each paper, to determine whether they were relevant to the review [9]. We used only the material that includes all of the search criteria in the main body of the text, as the first filter. Any article that appearing to be a hit with just one criteria matched will be dismissed from the study. The remaining article abstracts were reviewed for context and a further filter applied.

\subsection{Analysis and synthesis}

The aim of the analysis is to examine and dissect individual studies and explore how the components relate to one another. In contrast, synthesis is a process of putting the findings from individual studies together, as per Denyer and Tranfield, 2009, "into a new or different 
arrangement and developing knowledge that is not apparent from reading the individual studies in isolation" [9]. This analysis intends to identify how the research areas can be categorised and also the terminology used within this research area. It will identify the trend in publications in this research area to the present year. It is intended to use thematic synthesis, which is essentially a method to display what the research areas show from this qualitative study of literature. According to Bryman [26], there are three principal stages to thematic synthesis: The first stage is coding in the text. The main focus for the coding in this context was the text in the abstract of each article. The second and third stages were for identifying higher order themes, which are produced by combining the many codes. Due to the relatively small sample size of this study, only the one level was used.

\subsection{Reporting and use of research results}

The intention and purpose of a systematic review is not to present advice, but to provide researchers with a sound understanding of the knowledge of the research area and gaps within. Although there is a plethora of research on sustainable development, the circular economy is less popular. There is a wide range of topics about the circular economy, such as industry in China and the supply chain in general. In our systematic literature review, we identified a total of 21 articles with some significance for manufacturing and the circular economy.

\section{FINDINGS AND DISCUSSION}

\subsection{Descriptive analysis of findings}

We noted from this study that the majority of research articles were either identified at the Meso (industrial parks) or Macro level (cites, regions), with the smallest number of studies aimed at the micro level (single company or consumer). Of the studies at the micro level, it was interesting to note that there were very few studies directly relating to a SME. Ruggieri et al. [10] argued that through the study of existing literature, a plethora of studies around circular economy applications was found, but there was little attention to the implications of cooperation among different business organizations. Based on this premise, Ruggieri et al. [10] set out to answer the question: "Which factors impact on the cooperation among different business organizations for the development of circular approaches?" They subsequently analysed "three cases, belonging to different industries, all located in the Lazio Region, central Italy." Their discussion around SMEs suggests the exchange of waste through symbiotic relationships. They recognise the difficulty with this, and also suggest the emergence of a third party intermediary that collects waste and then processes waste streams for other industries, which the author considers to be more feasible. Rizos et al. [11] also state "In short, it is much easier to create a green SME than to make an already existing company greener." Nevertheless, the question remains: What does this mean to a SME in terms of resources, skills, attitudes, etc.?

According to Lieder and Rashid [12], "Most relevant, analyses and discussions about CE and towards CE development is to largest extent done from a resource scarcity and environmental impact perspective leaving economic benefits of industrial actors in general and specifically on individual level missing." Klewitz and Hansen [13] state "To the knowledge of the authors, no systematic review exists focusing on innovation practices of SMEs to date." However, their research focuses on sustainable-oriented innovation with SMEs, but not a circular economy. Whilst both sustainable development and sustainable 
Table 3: All-inclusive articles from the systematic literature review.

\begin{tabular}{|c|c|c|c|}
\hline Author(s) & Title & Database & Journal \\
\hline $\begin{array}{l}\text { (Ghis ellini, Cialani and Ulgiati, } \\
\text { 2016b) }\end{array}$ & $\begin{array}{l}\text { A review on circular economy: the expected } \\
\text { transition to a balanced interplay of environmental } \\
\text { and economic systems }\end{array}$ & $\begin{array}{l}\text { Google } \\
\text { Scholar }\end{array}$ & $\begin{array}{l}\text { Journal of Cleaner } \\
\text { Production }\end{array}$ \\
\hline (Bocken, Bakker and Pauw, 2016) & $\begin{array}{l}\text { Product design and business model strategies for } \\
\text { a circular economy }\end{array}$ & $\mathrm{T} \& \mathrm{~F}$ & $\begin{array}{l}\text { Journal of Industrial and } \\
\text { Production Engineering }\end{array}$ \\
\hline (Niero and Hauschild, 2017) & $\begin{array}{l}\text { Closing the loop for packaging: finding a } \\
\text { framework to operationalize Circular Economy } \\
\text { strategies }\end{array}$ & Elsevier & $\begin{array}{l}\text { Journal of Industrial and } \\
\text { Production Engineering }\end{array}$ \\
\hline $\begin{array}{l}\text { (Rizos, Vasileios Behrens, Arno van } \\
\text { der Gaast, et al 2016) }\end{array}$ & $\begin{array}{l}\text { Implementation of Circular Economy Business } \\
\text { Models by Small and Medium-Sized Enterprises } \\
\text { (SMEs): Barriers and Enablers }\end{array}$ & $\begin{array}{l}\text { Google } \\
\text { Scholar }\end{array}$ & CEPS \\
\hline $\begin{array}{l}\text { (Kirchherr, Julian Reike, Denise } \\
\text { Hekkert, Marko 2017) }\end{array}$ & $\begin{array}{l}\text { Conceptualizing the circular economy: An } \\
\text { analys is of } 114 \text { definition }\end{array}$ & Elsevier & $\begin{array}{l}\text { Resources, Conservation } \\
\text { and Recycling }\end{array}$ \\
\hline $\begin{array}{l}\text { (De los Rios, Irel Carolina } \\
\text { Charnley, Fiona J.S. 2017) }\end{array}$ & $\begin{array}{l}\text { Skills and capabilities for a sustainable and } \\
\text { circular economy: The changing role of design }\end{array}$ & Els evier & $\begin{array}{l}\text { Journal of Cleaner } \\
\text { Production }\end{array}$ \\
\hline $\begin{array}{l}\text { (Ruggieri, Alessandro Braccini, } \\
\text { Alessio MariaMosconi, Enrico } \\
\text { Maria 2016) }\end{array}$ & $\begin{array}{l}\text { A meta-model of inter-organis ational cooperation } \\
\text { for the transition to a circular economy }\end{array}$ & $\begin{array}{l}\text { Google } \\
\text { Scholar }\end{array}$ & $\begin{array}{l}\text { Sustainability } \\
\text { (Switzerland) }\end{array}$ \\
\hline $\begin{array}{l}\text { (Huysman, SofieDe Schaepmeester, } \\
\text { Jonas Ragaert, KimDewulf, JoDe } \\
\text { Meester, Steven 2017) }\end{array}$ & $\begin{array}{l}\text { Performance indicators for a circular economy: A } \\
\text { case study on post-industrial plastic waste }\end{array}$ & Els evier & $\begin{array}{l}\text { Resources, Conservation } \\
\text { and Recycling }\end{array}$ \\
\hline $\begin{array}{l}\text { (Elia, Valerio Gnoni, Maria Grazia } \\
\text { Tornese, Fabiana 2016) }\end{array}$ & $\begin{array}{l}\text { Measuring circular economy strategies through } \\
\text { index methods: A critical analys is }\end{array}$ & Elsevier & $\begin{array}{l}\text { Journal of Cleaner } \\
\text { Production }\end{array}$ \\
\hline $\begin{array}{l}\text { (Geis sdoerfer, Martin Savaget, } \\
\text { PauloBocken, Nancy M.P. Hultink, } \\
\text { Erik Jan 2017) }\end{array}$ & $\begin{array}{l}\text { The Circular Economy - a new sustainability } \\
\text { paradigm? }\end{array}$ & Elsevier & $\begin{array}{l}\text { Journal of Cleaner } \\
\text { Production }\end{array}$ \\
\hline $\begin{array}{l}\text { (Hobson, Kersty Lynch, Nicholas } \\
\text { 2016) }\end{array}$ & $\begin{array}{l}\text { Diversifying and de-growing the circular } \\
\text { economy: Radical social trans formation in a } \\
\text { resource-s carce world }\end{array}$ & Elsevier & Futures \\
\hline (Lewandowski, Mateusz 2016) & $\begin{array}{l}\text { Designing the Business Models for Circular } \\
\text { Economy-Towards the Conceptual Framework }\end{array}$ & $\begin{array}{l}\text { Google } \\
\text { Scholar }\end{array}$ & $\begin{array}{l}\text { Sustainability } \\
\text { (Switzerland) }\end{array}$ \\
\hline $\begin{array}{l}\text { (George, Donald A R Chi, BrianLin, - } \\
\text { Ang Chen, Yunmin 2015) }\end{array}$ & A circular economy model of economic growth & Elsevier & $\begin{array}{l}\text { Environmental } \\
\text { Modelling and Software }\end{array}$ \\
\hline $\begin{array}{l}\text { (Franklin-Johns on, ElizabethFigge, } \\
\text { Frank Canning, Louise 2016) }\end{array}$ & $\begin{array}{l}\text { Resource duration as a managerial indicator for } \\
\text { Circular Economy performance }\end{array}$ & Elsevier & $\begin{array}{l}\text { Journal of Cleaner } \\
\text { Production }\end{array}$ \\
\hline $\begin{array}{l}\text { (Niero, MoniaOlsen, Stig Irving } \\
\text { 2015) }\end{array}$ & $\begin{array}{l}\text { Circular economy: To be or not to be in a closed } \\
\text { product loop? A Life Cycle Assessment of } \\
\text { aluminium cans with inclusion of alloying } \\
\text { elements }\end{array}$ & Elsevier & $\begin{array}{l}\text { Resources, Conservation } \\
\text { and Recycling }\end{array}$ \\
\hline $\begin{array}{l}\text { (Sauvé, SébastienBernard, } \\
\text { SophieSloan, Pamela 2016) }\end{array}$ & $\begin{array}{l}\text { Environmental sciences, sustainable development } \\
\text { and circular economy: Alternative concepts for } \\
\text { trans-disciplinary research }\end{array}$ & Els evier & $\begin{array}{l}\text { Environmental } \\
\text { Development }\end{array}$ \\
\hline (Lieder, Michael Rashid, Amir 2016) & $\begin{array}{l}\text { Towards circular economy implementation: a } \\
\text { comprehensive review in context of manufacturing } \\
\text { industry }\end{array}$ & Els evier & $\begin{array}{l}\text { Journal of Cleaner } \\
\text { Production }\end{array}$ \\
\hline (Jawahir, I S Bradley, Ryan 2016) & $\begin{array}{l}\text { Technological Elements of Circular Economy and } \\
\text { the Principles of 6R-Based Closed-loop Material } \\
\text { Flow in Sustainable Manufacturing }\end{array}$ & Els evier & Procedia CIRP \\
\hline (Witjes, Sjors Lozano, Rodrigo 2016) & $\begin{array}{l}\text { Towards a more Circular Economy: Proposing a } \\
\text { framework linking sustainable public procurement } \\
\text { and sustainable business models }\end{array}$ & Elsevier & $\begin{array}{l}\text { Resources, Conservation } \\
\text { and Recycling }\end{array}$ \\
\hline $\begin{array}{l}\text { (Leino, Maija Pekkarinen, Joonas } \\
\text { Soukka, Ris to 2016) }\end{array}$ & $\begin{array}{l}\text { The role of laser additive manufacturing methods } \\
\text { of metals in repair, refurbishment and } \\
\text { remanufacturing - Enabling circular economy }\end{array}$ & Els evier & Physics Procedia \\
\hline $\begin{array}{l}\text { (Korse, M. Ruitenburg, R.J. } \\
\text { Toxopeus, M.E. } \\
\text { Braaksma, A.J.J. 2016) }\end{array}$ & $\begin{array}{l}\text { Embedding the Circular Economy in Investment } \\
\text { Decision-making for Capital Assets - A Business } \\
\text { Case Framework }\end{array}$ & Elsevier & $\begin{array}{l}\text { 23rd CIRP conference on } \\
\text { Life Cycle Engineering }\end{array}$ \\
\hline
\end{tabular}




\section{Breakdown by Journal Articles}

23rd CIRP conference on Life Cycle.

Physics Procedia

Procedia CIRP

Environmental Development

Environmental Modelling and Software

Sustainability (Switzerland)

Futures

Resources, Conservation and Recycling

CEPS

Journal of Industrial and Production.

Journal of Cleaner Production
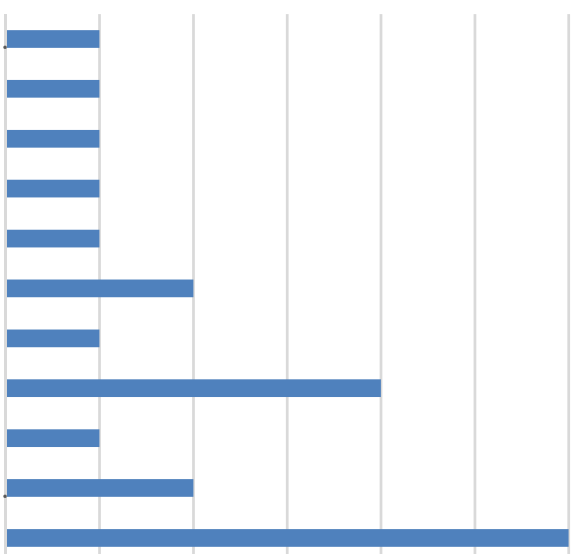

0

$\begin{array}{lll}2 & 3 & 4\end{array}$

56

Figure 1: Contributions from journals.

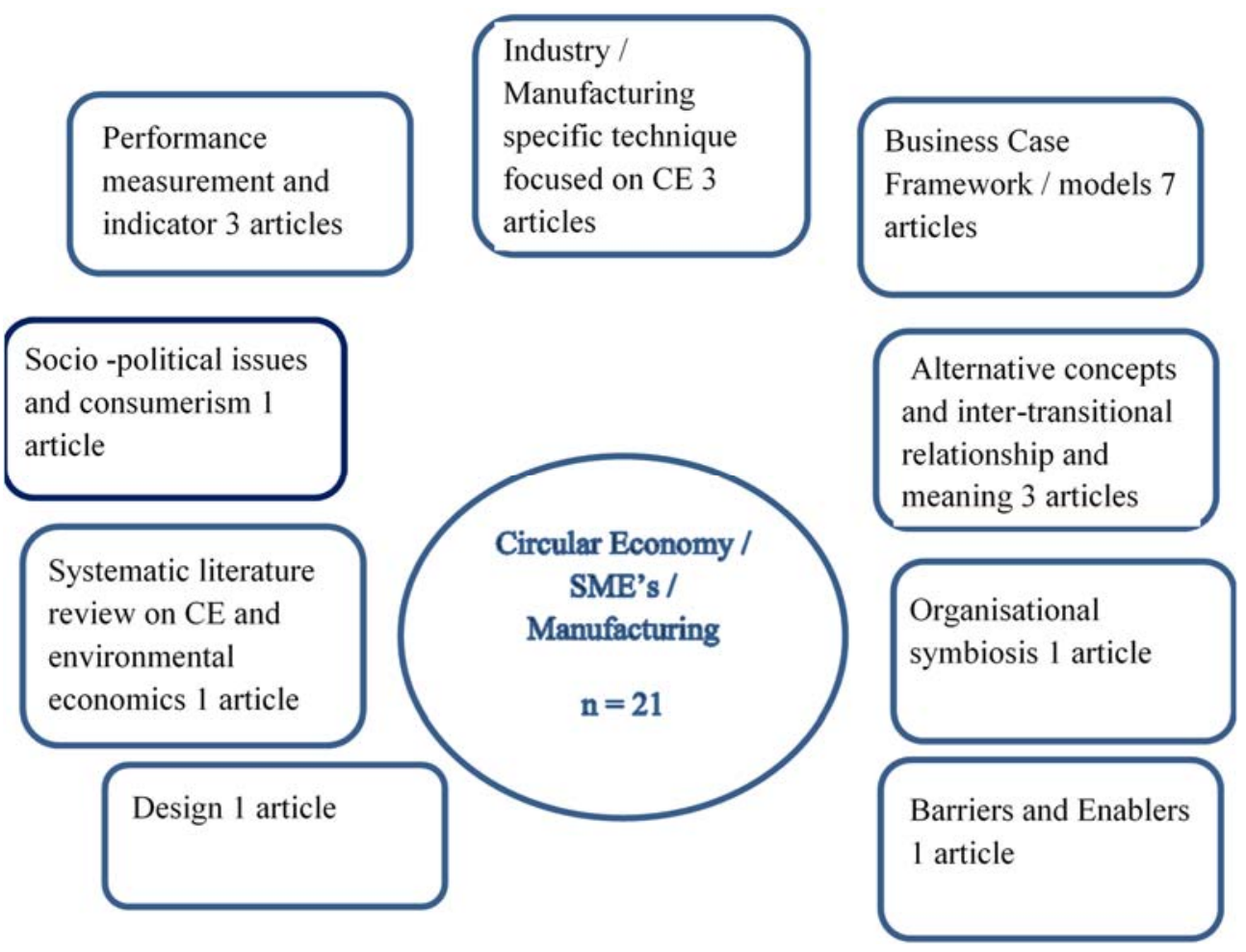

Figure 2: Thematic analysis of the systematic literature review. 
innovation share the same general theme as the circular economy, there is a fundamental difference. The circular economy can be defined as a "model of consumption and production," whereas sustainable development is a "societal objective" [14]. Sustainable development currently operates in a linear economy of take, make and dispose. The notions of recycling, reducing and reusing have been adopted in many SMEs throughout the UK, to a certain level. The idea of operating circular economy practices in SMEs would be fundamentally different. A circular economy "requires changing the paradigm of the linear economy where the external costs related to a series of environmental and human health issues are dissociated from the production and consumption of the goods. Instead, these costs need to be fully integrated in the price paid by the consumers."..."If the application of circular initiatives brings better results towards sustainability, then the circular economy becomes a tool for sustainable development" [14].

Law and Gunasekaran [15] argue that sustainability and change for an organisation comes from three factors, namely: management, external and internal factors. "These changes from external factors require management to not only address new issues, but also to substantially change existing practices and create new management systems." Schulte [1] argues that in order to accelerate the transition to a circular economy, political leaders and economists must recognise the need to move the tax from labour to levy a tax on non-renewable resource extraction. It is inevitable that the strategy for $\mathrm{CE}$ will be led from government policy and regulation. It is how individual SMEs are able to best respond to these policies and position themselves for continued competitive advantage; or in many cases survival.

Rizos et al. [11] conclude: "policy-makers need to first better understand the complex challenges faced by SMEs in order to develop appropriate supportive policy frameworks."

Lieder and Rashid [12] state "essential activities for successful CE implementation, such as business models, product design, supply chain design and choice of material are in control and hence finally determined by manufacturing companies with the underlying motivation of gaining economic benefits. In this scenario it is obvious that a transition towards the $\mathrm{CE}$ will not appear favourable for manufacturing companies since it will be perceived as a constraint to industrial activities rather than an opportunity for sustainable business and growth." The challenges regarding circular economy, for a SME, are to adapt to a future state model of sustainability. Based on their response to external pressures and regulation, they will have to transform their processes and practices [11], finding that "using language that is directly relevant to the core business operations, such as 'reduce waste' or 'reduce costs' can play a significant role in convincing SMEs of the benefits of the circular economy." This is suggestive that business leaders and owners may not hold a favourable attitude towards a circular economy. Silva et al. [16] concluded "that the current transitional state of waste management across the world requires the development of further government policy, planning and behaviour change." This notion is further supported by Law and Gunasekaran [15]: "Management mind-set thus plays an important role in the sustainability strategy adoption." It is clear that for a SME working towards a circular economy, that individual mind-sets, the way an individual thinks and behaves, are key factors supporting this transition.

The main barriers for a SME taking up circular economy initiatives are financial support and resources, in terms of skills and knowledge (according to Rizos et al. [11]). "SMEs lack awareness of technological innovation cycle and insufficient understanding of circular economy" [17]. Whilst the adoption of a circular economy offers clear tangible benefits to society, the environment and the planet; what are the perceived benefits to a SME adopting circular economy philosophy? According to Klewitz and Hansen [13], "We find that first 
SME strategic sustainability behaviour ranges from resistant, reactive, anticipatory, and innovation-based to sustainability-rooted."

A business case model includes the business objectives, as well as a cost/benefit analysis and risk valuation [18]. "Some SMEs appear not to be familiar with the circular economy concept or to face difficulties in understanding its benefits. Furthermore, SMEs do not often give priority to sustainability issues since they are more concerned with the day-to-day running of their businesses and the multiple challenges this presents" [11]. "However, due to competitive pressure environmental impacts will most likely remain unconsidered as primary focus is put on economic benefits and growth. Given the scenario that industrial businesses do not see (economic) advantages of CE will result in reluctance when it comes to pursuing CE initiatives" [12].

Lieder and Rashid [12] "conclude that CE relevant research has been and is an active area. However, it has evolved primarily as research on waste generation, resource use and environmental impact while neglecting business and economic perspectives. This neglect poses the risk of inhibiting CE implementation since advantages for industry are inexplicit."

They continue to state that only a comprehensive framework unique to the concept of CE that is jointly supported by all stakeholders is able to support successful CE implementation.

Franklin-Johnson et al. [19] present a complementary, non-monetary, value-based performance indicator in the context of the circular economy. To summarise, longevity uses time to measure the duration of a material within a product system, where greater retention means that resource use is maximised. The idea that an organisation must measure what is important and that this will drive their behaviour is a huge paradigm shift for SME managers. For example, Franklin-Johnson et al. [19] argue that design managers could use the longevity indicator to influence their decisions for keeping materials in the product for longer, to consider "enable continued material and product retention." For the procurement manager to consider "at the point of purchase and eventual replacement, product users might access information showing material and product longevity when making purchase decisions." According to Lewandowski [20], "there is a need for a comprehensive conceptual framework for the circular business model to support practitioners in the transition of their businesses towards circular economy."

"Circular business models are needed to stimulate and foster implementation of the circular economy on a micro-level" [20]. Moving forward, CE debates must include questions about the social, the citizen and consumption, which includes broadening the ontological toolkit in CE debates [21]. Industrial symbiosis, in the context of circular economy, is the level of cooperation and the relationships between individual SMEs regarding circular activity. According to Ruggieri et al. [10], "These business organizations can work together through the exchange of resources that are of less value if not exchanged, but that acquire value when shared, and targeted to specific uses" and this suggests targeting future research to further study inter-organisational symbiosis to support circular economy applications among business organizations.

"The need for a variety of design skills to support closed loops has been made evident within this work; ranging from deeper knowledge of material science, engineering techniques and operational processes, through to proficiencies in service design and a deep knowledge of human behaviour" [22].

From the data presented, re-occurring themes in the research population have been collated and demonstrate significant research into business case models and frameworks. Elia et al. [23] suggest that research about indicators and methodologies for measuring the application level of CE strategies is still in its earliest phase, particularly on the micro level. 
There are clearly going to be huge challenges for SMEs in terms of skills, knowledge, business models, and more importantly, changing mind-sets. In terms of business excellence, the ideas of driving down cost, being competitive, focusing on the customer, their needs and perceived quality, and delivering the right product in the right quantity at the right time and in the right place, is ever more crucial and the circular economy will not change this concept. These are typically the measures by which an SME will conduct business and strive to improve. Aquilani et al. [24] discuss the idea of co-creation, which they define as "joint creation and evolution of value with stake holding individuals." The concept being, here, that a SME can no longer stand alone, but enters into mutual win/win relationships creating value from waste. Traditional quality management principles don't go away, so they must be considered. Interestingly, the first column of Aquilani's integrated value creation process model is headed "a firm willingness to co-create value." Furthermore, they highlight the attitude of the leader, manager or business owner that may influence the culture of the company (SME) towards or against adopting a positive approach to circular economy opportunities and challenges. They also cite financial burden, lack of technical skills and general awareness, as contributors to the leader's attitude. Considering the three Law and Gunasekaran factors, namely; management, external and internal factors, many challenges from the external perspective will be orchestrated by policy makers, but the interpretation and subsequent responses of an SME will come from management and ultimately, their leadership and attitude.

If a SME is to review its role in the circular economy, then change is very much a requirement. The circular economy is built on the notion of reducing the use of virgin materials and using re-manufacturing or recycled materials from previous manufacturing products. De los Rios and Charnley [22] conclude that new skills are required, in terms of design, deeper knowledge around materials science, engineering techniques and operational processes. Designer skills need to have broader knowledge and act at different stages of the value chain. "Much research has been done on how companies can integrate environmental criteria into the product design and development stages. A significant number of methods and tools have been developed in order to provide relevant information for engineer designers and product developers about the environmental performance of the product" [25]. It may be necessary for design engineers in a SME to have broader contacts across the sector, to work collaboratively to realise mutual benefits in terms of a circular economy. Salari and Bhuiyan [25] stated: "one of the goals is to integrate different applicable tools with each other in such a way that the output of one could be used as an input of the other." This emphasises the need for not only deeper skills from the designers, but also a cross-organisational network to enable innovation, collaboration and inter-related mutual outcomes.

Motivators and readiness of SMEs for a circular economy are important factors to be considered. Law and Gunasekaran [15] identify key motivating factors for the adoption of sustainable development strategies. Having a circular economy is effectively the next generation of sustainable practice; therefore, will add to the challenges already presented to SMEs. Law and Gunasekaran [15] discuss a model; of Management, Internal and External (MIE) factors, and summarise that the internal factors and management policy have significant influence in achieving a sustainable development. This must also be true from a CE perspective. Strategically, the managers and leaders from SMEs must be able to identify the strategic competitive advantage associated with investment into changing their product and process to realise benefits. 


\section{CONCLUSIONS}

It is clear from the research into "circular economy" the impact it will have at the micro level on SMEs is fairly limited. The skills required in terms of materials and design, as well as the need for organisational change, are highlighted as areas for further research. There must be more research into policy and government interventions. There must be research identifying key performance indicators and frameworks, to enable an organisation to transition to circular practices. It is also evident that there is a lack of appetite from SMEs, in terms of business leaders and owners thinking about the economic benefits, which will require a paradigm shift in business thinking at the SME level.

\section{REFERENCES}

[1] Schulte, U.G., New business models for a radical change in resource efficiency. Environ. Innov. Soc. Transitions, 9, pp. 43-47, 2013. DOI: 10.1016/j.eist.2013.09.006.

[2] Genovese, A., Acquaye, A.A., Figueroa, A. \& Koh, L.S., Sustainable supply chain management and the transition towards a circular economy: Evidence and some applications. Omega, pp. 1-14, 2015. www.sciencedirect.com/science/article/pii/S0305048315001322.

[3] Jurgilevich, A. et al., Transition towards circular economy in the food system. Sustain, 8(1), pp. 1-14, 2016.

[4] Jawahir, I.S. \& Bradley, R., Technological elements of circular economy and the principles of 6R-based closed-loop material flow in sustainable manufacturing. Procedia CIRP, 40, pp. 103-108, 2016. DOI: 10.1016/j.procir.2016.01.067.

[5] Tranfield, D., Denyer, D. \& Smart, P., Towards a methodology for developing evidence-informed management knowledge by means of systematic review. $B r . J$. Manag., 14, pp. 207-222, 2003.

[6] Grant, M.J. \& Booth, A., A typology of reviews: An analysis of 14 review types and associated methodologies. Health Info. Libr. J., 26(2), pp. 91-108, 2009.

[7] Xavier, A.F., Naveiro, R.M., Aoussat, A. \& Reyes, T., Systematic literature review of eco-innovation models: Opportunities and recommendations for future research. $J$. Clean. Prod., 149, pp. 1278-1302, 2017.

[8] Sauvé, S., Bernard, S. \& Sloan, P., Environmental sciences, sustainable development and circular economy: Alternative concepts for trans-disciplinary research. Environmental Development, 17, 48-56, 2016.

[9] Briner, R.B. \& Denyer, D., Systematic review and evidence synthesis as a practice and scholarship tool. The Oxford Handbook of Evidence-Based Management, ed. D. Rousseau, Oxford University Press: New York, 112-129, 2012.

[10] Ruggieri, A., Braccini, A.M., Poponi, S. \& Mosconi, E.M., A meta-model of interorganisational cooperation for the transition to a circular economy. Sustain, 8(11), pp. 1-17, 2016.

[11] Rizos, V., Behrens, A., Kafyeke, T., Hirschnitz-Garbers, M. \& Ioannou, A., The circular economy: Barriers and opportunities for SMEs. Ceps, 25(412), 2015. www.ceps.eu/publications/circular-economy-barriers-and-opportunities-smes.

[12] Lieder, M. \& Rashid, A., Towards circular economy implementation: A comprehensive review in context of manufacturing industry. J. Clean. Prod., 115, pp. 36-51, 2016. DOI: 10.1016/j.jclepro.2015.12.042.

[13] Klewitz, J. \& Hansen, E.G., Sustainability-oriented innovation of SMEs: A systematic review. J. Clean. Prod., 65, pp. 57-75, 2014. DOI: 10.1016/j.jclepro.2013.07.017. 
[14] Sauvé, S., Bernard, S. \& Sloan, P., Environmental sciences, sustainable development and circular economy: Alternative concepts for trans-disciplinary research. Environmental Development, 17, pp. 48-56, 2016. DOI: 10.1016/j.envdev.2015.09.002.

[15] Law, K.M.Y. \& Gunasekaran, A., Sustainability development in high-tech manufacturing firms in Hong Kong: Motivators and readiness. Int. J. Prod. Econ., 137(1), pp. 116-125, 2012. DOI: 10.1016/j.ijpe.2012.01.022.

[16] Silva, A., Rosano, M., Stocker, L. \& Gorissen, L., From waste to sustainable materials management: Three case studies of the transition journey. Waste Manag., 61, pp. 547557, 2016. DOI: 10.1016/j.wasman.2016.11.038.

[17] Yongtao, W., SMEs in the circular economy development strategy. Management Science and Engineering, 9(4), pp. 76-80, 2015.

[18] Korse, M., Ruitenburg, R.J., Toxopeus, M.E. \& Braaksma, A.J.J., Embedding the circular economy in investment decision-making for capital assets - A business case framework. 23rd CIRP Conf. Life Cycle Eng., 48, pp. 425-430, 2016. http://linkinghub.elsevier.com/retrieve/pii/S2212827116302748.

[19] Franklin-Johnson, E., Figge, F. \& Canning, L., Resource duration as a managerial indicator for circular economy performance. J. Clean. Prod., 133, pp. 589-598, 2016. http://linkinghub.elsevier.com/retrieve/pii/S0959652616304784.

[20] Lewandowski, M., Designing the business models for circular economy towards the conceptual framework. Sustain, 8(1), pp. 1-28, 2016.

[21] Hobson, K. \& Lynch, N., Diversifying and de-growing the circular economy: Radical social transformation in a resource-scarce world. Futures, 82, pp. 15-25, 2016.

DOI: 10.1016/j.futures.2016.05.012.

[22] De los Rios, I.C. \& Charnley, F.J.S., Skills and capabilities for a sustainable and circular economy: The changing role of design. J. Clean. Prod., 2016. DOI: 10.1016/j.jclepro.2016.10.130.

[23] Elia, V., Gnoni, M.G. \& Tornese, F., Measuring circular economy strategies through index methods: A critical analysis. J. Clean. Prod., 142, pp. 1-11, 2016. DOI: 10.1016/j.jclepro.2016.10.196.

[24] Aquilani, B., Silvestri, C. \& Ruggieri, A., Sustainability, TQM and value co-creation processes: The role of critical success factors. Sustainability, 8, p. 995, 2016.

[25] Salari, M. \& Bhuiyan, N., A proposed approach to improve current sustainable product development. J. Ind. Prod. Eng., 33(5), pp. 297-307, 2016. www.tandfonline.com/doi/full/10.1080/21681015.2016.1172122.

[26] Bryman, A., Social Research Methods, 5th ed., Oxford University Press: Oxford, 2016. 